\title{
Diffusion of Cobalt in Single Crystal $\alpha$-Titanium
}

\author{
By Hideo Nakajima*, Masahiro Koiwa*, \\ Yasuhide Minonishi* and Sakai Ono*
}

\begin{abstract}
Diffusion coefficients of ${ }^{60} \mathrm{Co}$ in single crystal $\alpha$-Ti have been measured over the temperature range from $871 \mathrm{~K}$ to $1135 \mathrm{~K}$. It has been confirmed that cobalt exhibits extremely fast diffusion about five orders of magnitude faster than the self-diffusion in $\alpha$-Ti. The temperature dependence of the ${ }^{60} \mathrm{Co}$ diffusivities parallel and perpendicular to the $\mathrm{c}$ axis is expressed as

$$
\begin{aligned}
& D_{/ /}=1.9 \times 10^{-6} \exp \left\{-(114.1 \pm 0.9) \mathrm{kJ} \cdot \mathrm{mol}^{-1} / R T\right\} \mathrm{m}^{2} \mathrm{~s}^{-1} \\
& D_{\perp}=3.2 \times 10^{-6} \exp \left\{-(126.1 \pm 1.2) \mathrm{kJ} \cdot \mathrm{mol}^{-1} / R T\right\} \mathrm{m}^{2} \mathrm{~s}^{-1} .
\end{aligned}
$$

It is suggested that some interstitial-type mechanism is operative in the Co diffusion in $\alpha$-Ti.
\end{abstract}

(Received June 24, 1983)

Keyzerds: impurity diffusion, fast diffusion, diffusion mechanism, titanium, cobalt, single crystal

\section{Introduction}

The knowledge of diffusion coefficients of atoms in crystals is essential for the understanding of various processes occurring in materials. In the case of non-cubic metals, diffusion is anisotropic; the diffusion coefficients along the principal crystallographic directions should be determined by experiments using single crystal specimens.

The metal titanium, which undergoes the $\alpha(h c p) \leftrightarrow \beta(b c c)$ transformation at $1155 \mathrm{~K}$, is being used as industrial materials, and the increasing use is expected in various branches of technology. However, there has been no determination of the self- or impurity diffusion in single crystal titanium, probably because of the difficulty of growing single crystal specimens large enough for diffusion experiments.

Previous data ${ }^{(1)-(8)}$ on diffusion in polycrystalline titanium are summarized in Fig. 1. Impurity diffusion coefficients in $\alpha$-titanium have been measured for $\mathrm{Ni}, \mathrm{Co}$ and $\mathrm{Mn}^{(5)(6)}$. It is noted that all the three transition metal elements exhibit fast diffusion; near the upper temperature limit of the $h c p$ phase the impurity diffusion coefficients are $10^{3}$ to $10^{5}$ times as large as that for self-diffusion ${ }^{(4)(8)}$. For the understanding of the mechanism of fast diffu-

* The Research Institute for Iron, Steel and Other Metals, Tohoku University, Sendai 980, Japan.

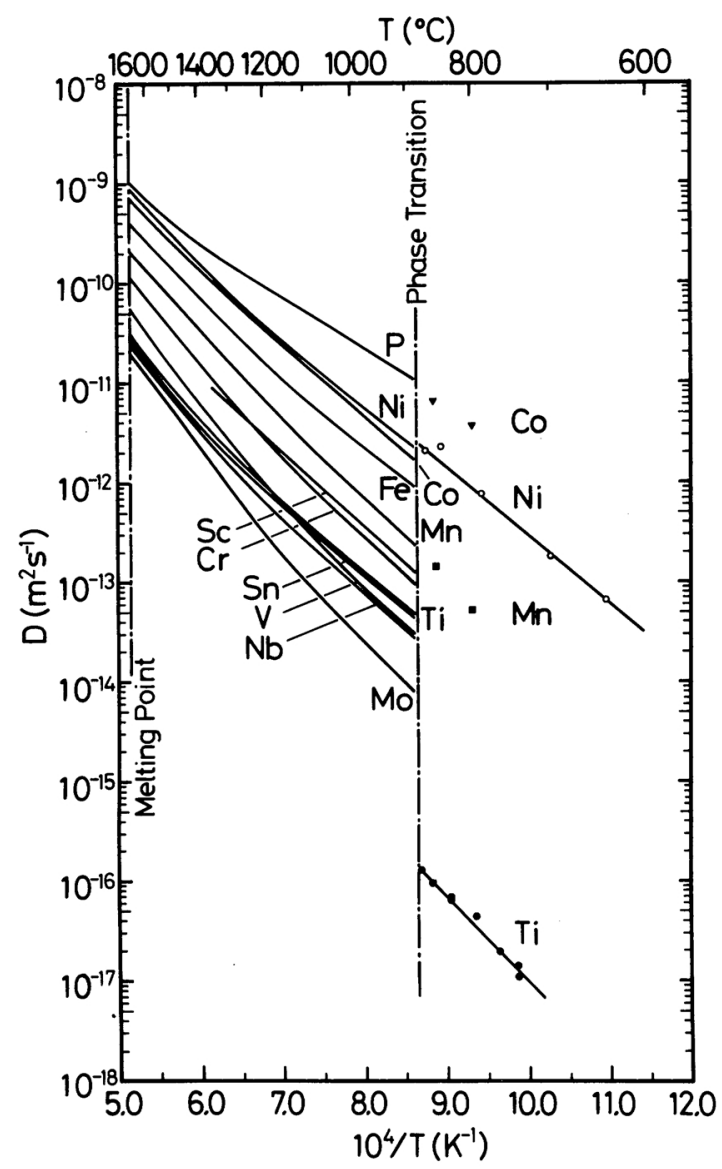

Fig. 1 Temperature dependence of self and solute diffusion in Ti. $\mathrm{Ni}$ in $\alpha-\mathrm{Ti}^{(5)}$; Co and $\mathrm{Mn}$ in $\alpha-\mathrm{Ti}^{(6)}$; $\mathrm{Ti}$ in $\alpha-\mathrm{Ti}^{(4)(8)} ; \mathrm{Ni}, \mathrm{Co}, \mathrm{Fe}, \mathrm{Mn}, \mathrm{Nb}$ and $\mathrm{Mo}$ in $\beta$ $\mathrm{Ti}^{(1)} ; \mathrm{V}$ in $\beta-\mathrm{Ti}^{(2)} ; \mathrm{P}, \mathrm{Sc}$ and $\mathrm{Sn}$ in $\beta-\mathrm{Ti}^{(3)} ; \mathrm{Ti}$ in $\beta-\mathrm{Ti}^{(2)(7)}$. 
Gaussian, without serious holdup or noticeable non-Gaussian "tails". It is noted here that non-Gaussian profiles were observed in several systems which exhibited fast diffusion: $\mathrm{Ni}$ in $\alpha-\mathrm{Ti}^{(5)}$, and $\mathrm{Co}, \mathrm{Ni}$ and $\mathrm{Cu}$ in $\alpha-\mathrm{Zr}^{(5)(9)}$. The diffusivities obtained at each temperature are listed in Table 2. Temperature dependence of the diffusivities parallel and perpendicular to the $\mathrm{c}$ axis is shown in Fig. 3.

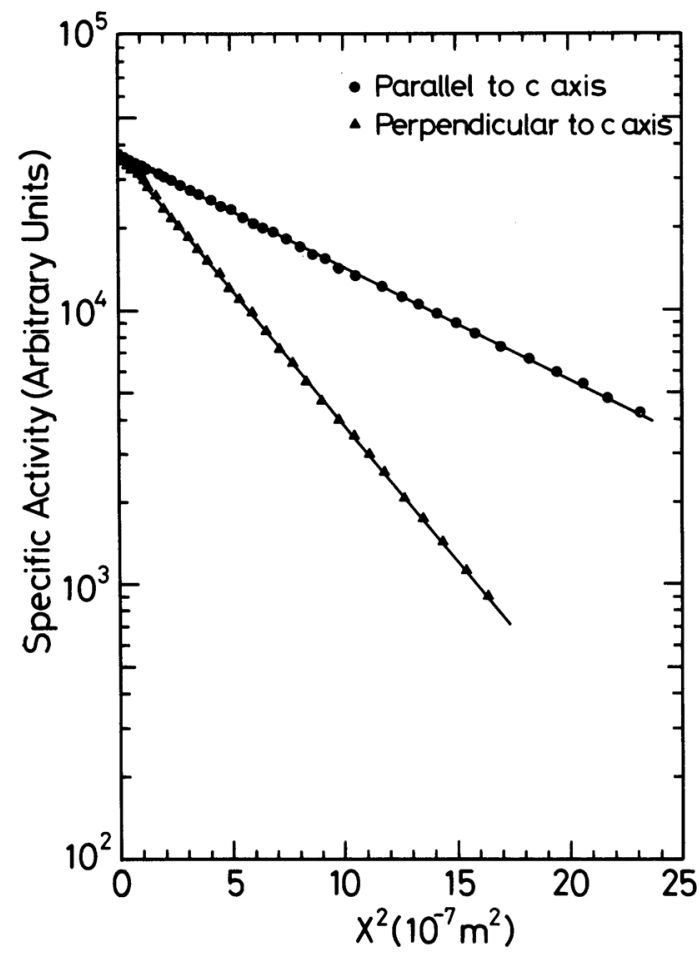

Fig. 2 Typical diffusion-penetration profiles at $980 \mathrm{~K}$.
Least-mean-squares analyses of the present data yield the following expressions for the temperature dependence of ${ }^{60} \mathrm{Co}$ diffusion in $\alpha-\mathrm{Ti}$ :

$$
\begin{aligned}
D_{/ /}= & 1.9 \times 10^{-6} \\
& \times \exp \left(-\frac{114.1 \pm 0.9 \mathrm{~kJ} / \mathrm{mol}}{R T}\right) \mathrm{m}^{2} \mathrm{~s}^{-1}
\end{aligned}
$$

and

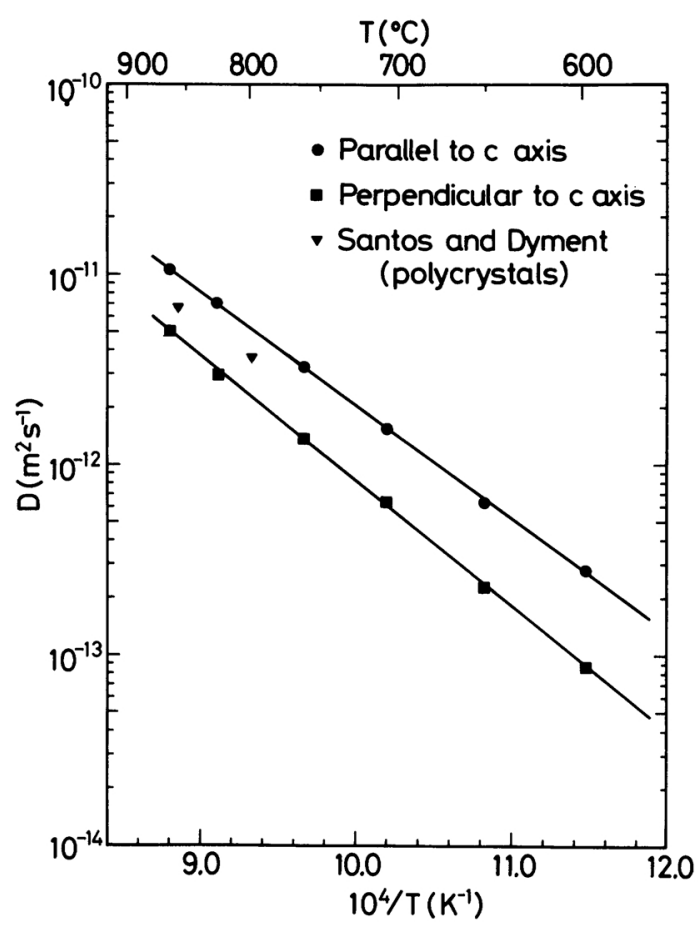

Fig. 3 Temperature dependence of diffusivities of ${ }^{60} \mathrm{Co}$ in $\alpha$-Ti.

\begin{tabular}{|c|c|c|c|c|}
\hline$\underset{(\mathbf{K})}{\text { Temperature }}$ & $\begin{array}{l}\text { Diffusion } \\
\text { direction }\end{array}$ & $\begin{array}{l}\text { Annealing } \\
\text { time(s) }\end{array}$ & $\begin{array}{l}\text { Diffusivity } \\
D\left(\mathrm{~m}^{2} \mathrm{~s}^{-1}\right)\end{array}$ & $D_{I /} / D_{\perp}$ \\
\hline $\begin{array}{l}1135.2 \pm 0.3 \\
1135.2 \pm 0.3\end{array}$ & $\frac{1}{11}$ & $\begin{array}{l}3.091 \times 10^{4} \\
3.091 \times 10^{4}\end{array}$ & $\begin{array}{l}(5.066 \pm 0.061) \times 10^{-12} \\
(1.054 \pm 0.001) \times 10^{-11}\end{array}$ & $2.08 \pm 0.01$ \\
\hline $\begin{array}{l}1096.7 \pm 0.2 \\
1097.4 \pm 0.2\end{array}$ & $\frac{1}{11}$ & $\begin{array}{l}7.956 \times 10^{4} \\
5.784 \times 10^{4}\end{array}$ & $\begin{array}{l}(2.937 \pm 0.011) \times 10^{-12} \\
(7.082 \pm 0.048) \times 10^{-12}\end{array}$ & $2.41 \pm 0.01$ \\
\hline $\begin{array}{l}1034.1 \pm 0.3 \\
1033.9 \pm 0.2\end{array}$ & $\frac{1}{11}$ & $\begin{array}{l}1.259 \times 10^{5} \\
4.065 \times 10^{4}\end{array}$ & $\begin{array}{l}(1.394 \pm 0.012) \times 10^{-12} \\
(3.263 \pm 0.004) \times 10^{-12}\end{array}$ & $2.34 \pm 0.01$ \\
\hline $\begin{array}{l}980.0 \pm 0.3 \\
980.0 \pm 0.3\end{array}$ & $\frac{1}{11}$ & $\begin{array}{l}1.706 \times 10^{5} \\
1.706 \times 10^{5}\end{array}$ & $\left(\begin{array}{l}6.420 \pm 0.014) \times 10^{-13} \\
(1.561 \pm 0.004) \times 10^{-12}\end{array}\right.$ & $2.43 \pm 0.01$ \\
\hline $\begin{array}{l}923.4 \pm 0.2 \\
923.4 \pm 0.2\end{array}$ & $\frac{1}{1 /}$ & $\begin{array}{l}4.550 \times 10^{5} \\
4.550 \times 10^{5}\end{array}$ & $\begin{array}{l}(2.250 \pm 0.006) \times 10^{-13} \\
(6.221 \pm 0.012) \times 10^{-13}\end{array}$ & $2.77 \pm 0.01$ \\
\hline $\begin{array}{l}871.2 \pm 0.2 \\
871.2 \pm 0.2\end{array}$ & $\frac{1}{11}$ & $\begin{array}{l}6.326 \times 10^{5} \\
6.326 \times 10^{5}\end{array}$ & $\begin{array}{l}(8.627 \pm 0.025) \times 10^{-14} \\
(2.822 \pm 0.010) \times 10^{-13}\end{array}$ & $3.27 \pm 0.01$ \\
\hline
\end{tabular}

Table 2 Diffusivities of ${ }^{60} \mathrm{Co}$ measured in $\alpha-\mathrm{Ti}$. 
sion, the diffusion anisotropy should be first determined by measurements with single crystals.

The present paper reports the temperature dependence of the diffusivity of ${ }^{60} \mathrm{Co}$ in the $\alpha$ phase single crystal titanium.

\section{Experimental Procedure}

Single crystals about $150 \mathrm{~mm}$ in length and $11 \mathrm{~mm}$ in diameter were grown from highpurity titanium by an electron beam floating zone melting technique. Chemical analysis of the single crystals used for the present work is shown in Table 1. The single crystals were oriented with an accuracy better than $0.035 \mathrm{rad}$ $\left(2^{\circ}\right)$ either parallel or normal to the $\mathrm{c}$ axis by back-reflection Laue diffraction, and were cut into discs $4 \mathrm{~mm}$ thick using a multiwire saw.

The specimens were annealed for $1.21 \mathrm{Ms}$ (14 days) at $1143 \mathrm{~K}$, i.e. just below the $\alpha \rightarrow \beta$ transformation temperature. In order to avoid possible contamination during annealing, they were first wrapped with titanium foils and then with zirconium foils, and were sealed in a quartz tube filled with high-purity argon of about $3 \times 10^{4} \mathrm{~Pa}$; zirconium foils were used to prevent the reaction of titanium with quartz. For some specimens back-reflection Laue photographs were taken after the annealing to confirm the quality and the orientation.

Radioactive ${ }^{60} \mathrm{Co}$ was purchased from Amersham International Ltd. in the form of $\mathrm{CoCl}_{2}$ in $2.5 \mathrm{kmol} / \mathrm{m}^{3}$ (N) $\mathrm{HCl}$ solution. ${ }^{60} \mathrm{Co}$ was isolated from trace of $\mathrm{Ni}, \mathrm{Fe}$ and other impurities by cation exchange chromatography. The specific activity of the purified ${ }^{60} \mathrm{Co}$ was

Table 1 Chemical analysis of single crystal Ti.

\begin{tabular}{cc}
\hline Impurity & Concentration (mass ppm) \\
\hline $\mathrm{Mg}$ & $\mathrm{ND}$ \\
$\mathrm{Al}$ & $\mathrm{ND}$ \\
$\mathrm{Si}$ & $\mathrm{ND}$ \\
$\mathrm{Mn}$ & $\mathrm{ND}$ \\
$\mathrm{Cl}$ & $<10$ \\
$\mathrm{Fe}$ & $<10$ \\
$\mathrm{H}$ & $<10$ \\
$\mathrm{C}$ & 30 \\
$\mathrm{~N}$ & $<10$ \\
$\mathrm{O}$ & 330 \\
\hline \hline
\end{tabular}

around $1.3 \times 10^{15} \mathrm{~Bq} / \mathrm{kg} \quad(35 \mathrm{mCi} / \mathrm{mg})$. The specimen surface was electroplated with a tracer plating solution prepared by diluting the radioactive ${ }^{60} \mathrm{Co}$, after evaporating the $\mathrm{HCl}$, with sodium cyanide solution; the $\mathrm{pH}$ of the solution was adjusted to be in a range from 11.0 to 11.5. A pair of plated specimens parallel and perpendicular to the $\mathrm{c}$ axis were usually placed face to face, wrapped with titanium and zirconium foils in the same way as mentioned above, and then sealed in a quartz tube at $3 \times$ $10^{4} \mathrm{~Pa}$ in high-purity argon with a piece of cobalt, which was used for suppression of the evaporation of the radioactive cobalt from the specimen surface.

The diffusion anneals were carried out at specified temperatures controlled within $\pm 0.3 \mathrm{~K}$. In order to avoid a possible effect of surface diffusion or evaporation, the lateral surface of specimens was removed by a lathe after diffusion anneals. Specimens were sectioned by the lathe to depths from $1.0 \mathrm{~mm}$ to $2.3 \mathrm{~mm}$. Sectioned chips were weighed on a precision torsion balance with an accuracy of $\pm 0.01 \mathrm{mg}$. The mass loss in the sectioning process was less than $1 \%$.

The specimen chips were dissolved in $1 \mathrm{ml}$ of the solution of $10 \%$ hydrofluoric acid, $40 \%$ nitric acid and $50 \%$ distilled water. The ${ }^{60} \mathrm{Co}$ activity was measured by a well-type Packard Modumatic VI NaI(Tl) scintillation counter. At least $3 \times 10^{4}$ counts were collected for each sample.

\section{Results}

The diffusion condition was equivalent to an infinitely thin source diffusing into a semiinfinite cylinder. The appropriate solution to the diffusion equation is

$$
C(x, t)=C_{0}(\pi D t)^{-1 / 2} \exp \left(-\frac{x^{2}}{4 D t}\right),
$$

where $C(x, t)$ is the tracer concentration at a depth $x$ after a diffusion interval $t, D$ is the tracer diffusivity, and $C_{0}$ is the initial concentration of a tracer at the surface.

A representative set of diffusion-penetration profiles, after the diffusion annealing at $980 \mathrm{~K}$, is shown in Fig. 2. All diffusion profiles were 


$$
\begin{aligned}
D_{\perp}= & 3.2 \times 10^{-6} \\
& \times \exp \left(-\frac{126.1 \pm 1.2 \mathrm{~kJ} / \mathrm{mol}}{R T}\right) \mathrm{m}^{2} \mathrm{~s}^{-1},
\end{aligned}
$$

where $D_{i /}$ and $D_{\perp}$ are diffusivities in the directions parallel and perpendicular to the c axis, respectively. No curvature in the Arrhenius plot is observed, which is in marked contrast to the various data in $\beta-\mathrm{Ti}^{(1)-(3)}$ exhibiting upward curvatures (see Fig. 1).

Diffusivities determined for any polycrystalline specimens are expected to lie in between $D_{/ /}$and $D_{\perp}$. In fact, the two data points determined by Santos and Dyment ${ }^{(6)}$ fall in between the two straight lines $\left(D_{/ /}\right.$and $\left.D_{\perp}\right)$, as seen in Fig. 3.

\section{Discussion}

The present investigation has confirmed high diffusivity of Co in $\alpha$-Ti; the Co diffusivity is about five orders of magnitude larger than the self-diffusivity, and the activation energy for Co diffusion is 0.67 or 0.75 of that for selfdiffusion, $168.9 \mathrm{~kJ} / \mathrm{mol}$, which was determined for polycrystalline specimens ${ }^{(8)}$. For such fast diffusion to occur via the same mechanism as that for self-diffusion, i.e. the vacancy mechanism, the binding energy of a vacancy to a cobalt atom is estimated to be of the order of $1 \mathrm{eV}^{(10)}$. If the vacancy mechanism is operative for Co diffusion, the addition of $\mathrm{Co}$ into $\mathrm{Ti}$ should enhance the solvent self-diffusion; vacancies introduced by the Co addition are also instrumental in the diffusion of titanium atoms. Unfortunately, there has been no investigation on the effect of Co addition on the self-diffusion in $\alpha$-titanium. However, such a measurement does exist for $\beta$-Ti. Santos and Dyment ${ }^{(6)}$ have concluded that "the solute enhancement of $\mathrm{Ti}$ self-diffusion rates is less than the theoretical minimum value expected for a vacancy mechanism". It seems not unreasonable to assume that a similar mechanism is operative for Co diffusion both in the $\alpha$ - and $\beta$-Ti; it is unlikely to consider that Co atoms move in $\alpha$-Ti via the vacancy mechanism.

Fast diffusion of metallic solute elements in metal crystals was first recognized for Au diffusion in $\mathrm{Pb}$ in $1896^{(11)}$. In 1960 and thereabout, a number of systems were found to exhibit fast diffusion with $\mathrm{Pb}, \mathrm{Sn}$, In and $\mathrm{Tl}$ as solvent metals. Various aspects of fast diffusion in metals have been reviewed by Peterson ${ }^{(12)}$, Turnbull $^{(13)}$, Anthony ${ }^{(14)}$, Miller ${ }^{(15)}$ and most recently by Warburton and Turnbull ${ }^{(16)}$. Fast diffusion has also been found for $\alpha$ - and $\beta$ $\mathrm{Zr}^{(4)(5)(9)(17)-(25)}$. In what follows we shall compare the $\mathrm{Ti}-\mathrm{Co}$ system with other systems which exhibit fast diffusion.

\section{Atomic size effect on diffusion}

Hood has demonstrated a correlation between atomic size and impurity diffusion in $\mathrm{Pb}$; smaller sized atoms diffuse faster (see Fig. 1 of Ref. [26]). For $\alpha-\mathrm{Zr}$, a family metal of $\alpha-\mathrm{Ti}$, there is fairly rich accumulation of impurity diffusion data. In Fig. 4, the diffusivity of various impurities in $\alpha-\mathrm{Ti}$ and $\alpha-\mathrm{Zr}$ is plotted as a function of atomic size. Here we adopt, as

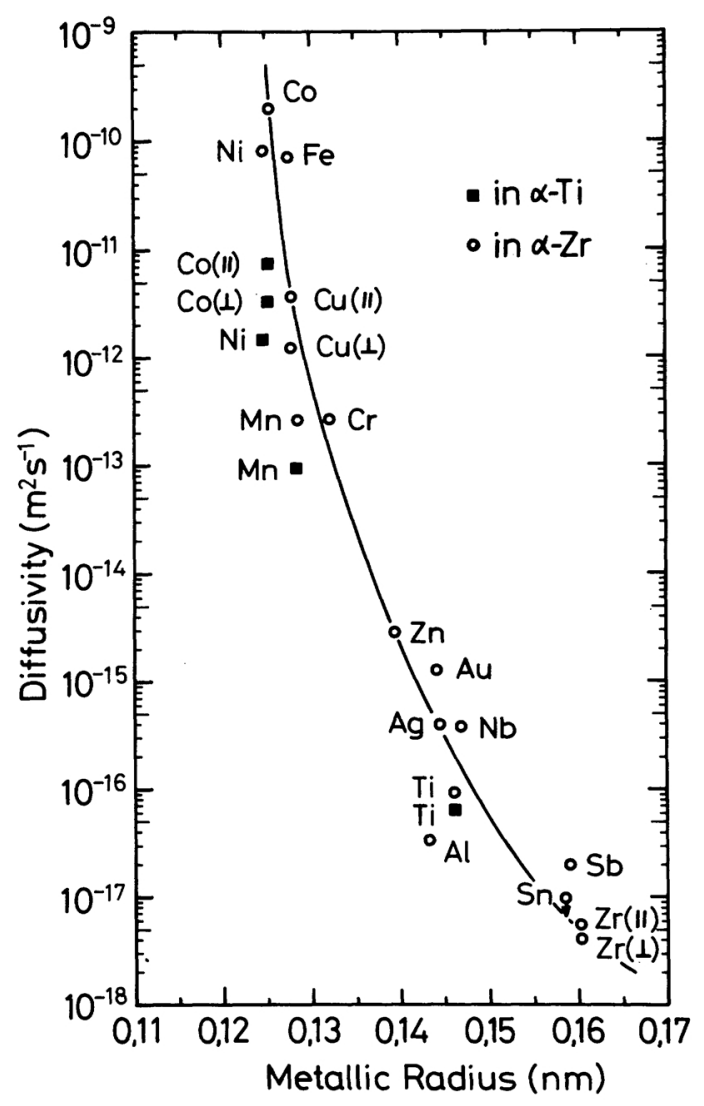

Fig. 4 Diffusivity versus metallic radius at $1100 \mathrm{~K}$ in $\alpha$-Ti and $\alpha-\mathrm{Zr}$. 
representing atomic size, "metallic radii for the coordination number 12 " after Teatum et al. (27) Numerical values are given in a tabulated form in the monograph by Pearson ${ }^{(28)}$. The radii were calculated by assuming a rigid sphere model from lattice spacings of crystals of the respective elements. For the case of non- $f c c$ crystals, the radius for the coordination number 12 was deduced by appropriate processing of original data. These radii are said to be the most suitable set to use for metallic alloys ${ }^{(28)}$.

As seen in the figure, the trend that smaller atoms diffuse faster is evident. In particular, $\mathrm{Co}$ and $\mathrm{Ni}$ are the smallest and the fastest both in $\alpha-\mathrm{Zr}$ and $\alpha$-Ti.

\section{Solubility versus diffusivity}

It is interesting to observe that fast diffusers have generally very low solubilities. In Fig. 5 are plotted the solubilities of various elements at $548 \mathrm{~K}$ in $\mathrm{Pb}$ versus the diffusivities at $548 \mathrm{~K}$. Such a correlation is found in fast diffusion in

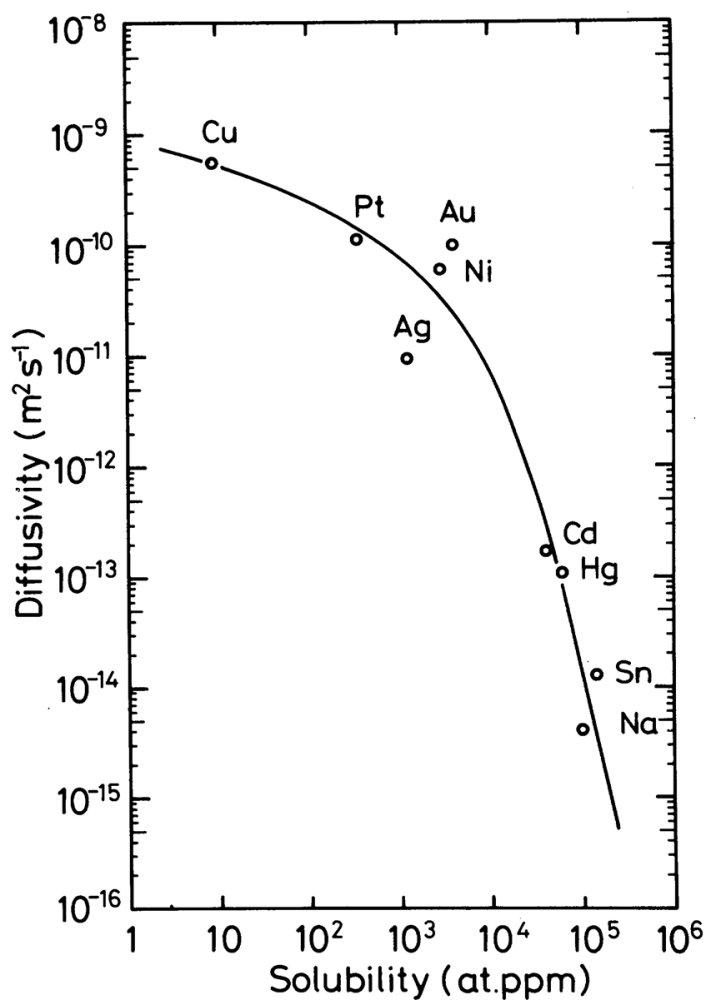

Fig. 5 Diffusivity versus solubility of various elements in $\mathrm{Pb}(T=548 \mathrm{~K})$.

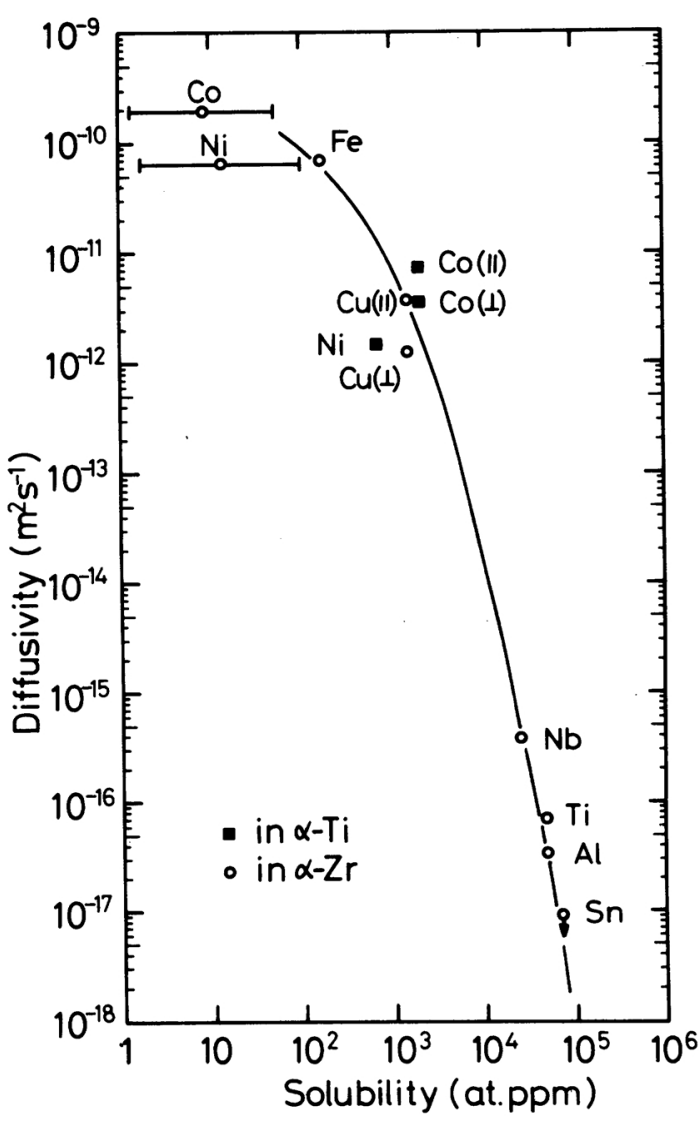

Fig. 6 Diffusivity versus solubility of various elements in $\alpha$-Ti and $\alpha-\operatorname{Zr}(T=1100 \mathrm{~K})$.

$\alpha-\mathrm{Ti}$ and $\alpha-\mathrm{Zr}$ as shown in Fig. 6 .

\section{Diffusion anisotropy}

The diffusion anisotropy of $\mathrm{Co}$ in $\alpha$-Ti is similar to those of noble metal elements in $\mathrm{Tl}^{(29)}$ and $\mathrm{Cu}$ in $\alpha-\mathrm{Zr}^{(24)}$;

(a) $D_{/ /}$is larger than $D_{\perp}$ by a factor of two to three

and

(b) $Q$ for diffusion parallel to the c axis is smaller than $Q$ perpendicular to the axis.

Hood and Schultz ${ }^{(24)}$ favoured an interstitial mechanism for $\mathrm{Cu}$ in $\alpha-\mathrm{Zr}$, and ascribed the above trend to the difference in volume of saddle point configurations for interstitial jumps in the two directions, parallel and perpendicular to the $\mathrm{c}$ axis. Since the $c / a$ ratio of $\mathrm{Ti}, 1.586$, is almost the same as that of $\mathrm{Zr}$, 1.594, the interpretation also holds for titanium. 


\section{Effect of phase transformation}

It is interesting to compare the change in the Co diffusivity with that in the self-diffusivity on transformation from the $\alpha(h c p)$ to the $\beta(b c c)$ phases. While the self-diffusion coefficient of titanium increases by about three orders of magnitude, the Co diffusivity does not show such a drastic change. Anthony et al. ${ }^{(29)}$ have observed a similar trend for thallium with $\mathrm{Au}$ and $\mathrm{Ag}$ as fast diffusers; while the self-diffusivity increases by about 30 times on transformation, $\mathrm{Au}$ and $\mathrm{Ag}$ diffusivities are almost continuous or rather slightly decrease across the transformation temperature of $505 \mathrm{~K}$. They regarded this as an indication of an interstitial type diffusion of $\mathrm{Au}$ and $\mathrm{Ag}$; if these impurities diffuse by the vacancy mechanism as in the case of self-diffusion, one should observe the increase in the diffusivity of the same order of magnitude as that for selfdiffusion. The same reasoning also applies to the Co diffusion in $\mathrm{Ti}$.

In summarizing, it is concluded that some type of interstitial mechanism is operative in the diffusion of cobalt in $\alpha$-titanium.

\section{Acknowledgements}

The authors wish to express their appreciation to Prof. S. Suzuki for the use of the facility at the Cyclotron Subcenter and to Dr. T. Mitsugashira for assistance in cation exchange chromatography. The titanium was supplied from Messrs. M. Terui and Y. Fujisaki of Nippon Mining Co., Ltd. One of the authors (H. N.) is grateful to the Sakkokai Foundation for the financial support.

\section{REFERENCES}

(1) G. B. Gibbs, D. Graham and D. H. Tomlin: Phil. Mag., 8 (1963), 1269.

(2) J. F. Murdock, T. S. Lundy and E. E. Stansbury: Acta Met., 12 (1964), 1033.

(3) J. Askill and G. B. Gibbs: Phys. Status Solidi, 11 (1965), 557.

(4) F. Dyment and C. M. Libanati: J. Mater. Sci., 3 (1968), 349.
(5) G. M. Hood and R. J. Schultz: Phil. Mag., 26 (1972), 329.

(6) E. Santos and F. Dyment: Phil. Mag., 31 (1975), 809.

(7) A. E. Pontau and D. Lazarus: Phys. Rev., B19 (1979), 4027.

(8) F. Dyment: Titanium '80 Science and Technology, Ed. by H. Kimura and O. Izumi, The Metallurgical Society of AIME, (1980), p. 519.

(9) G. V. Kidson: Phil. Mag., A44 (1981), 341.

(10) H. Nakajima and M. Koiwa: to be published.

(11) W. C. Roberts-Austen: Proc. Roy. Soc., 59 (1896), 281.

(12) N. L. Peterson: Solid State Phys., 22 (1968), 409.

(13) D. Turnbull: Proc. Mem. Lecture Meeting, 10th Ann. of Nat. Res. Inst. Metals, Tokyo, (1966), p. 1.

(14) T. R. Anthony: Vacancies and Interstitials in Metals, Ed. by A. Seeger et al., North-Holland Publ., Amsterdam, (1970), p. 935.

(15) J. W. Miller: Diffusion Processes, Ed. by J. N. Sherwood et al., Vol. 1, Gordon \& Breach, New York, (1971), p. 203.

(16) W. K. Warburton and D. Turnbull: Diffusion in Solids (Recent Developments), Ed. by A. S. Nowick and J. J. Burton, Academic Press, New York, (1975), p. 171.

(17) G. Kidson and J. McGurn: Can. J. Phys., 39 (1961), 1146.

(18) G. V. Kidson and G. J. Young: Phil. Mag., 20 (1969), 1047.

(19) G. M. Hood: Diffusion Processes, Ed. by J. N. Sherwood et al., Vol. 1, Gordon \& Breach, New York, (1971), p. 361.

(20) R. Tendler and C. F. Varotto: J. Nucl. Mater., 44 (1972), 99.

(21) R. Tendler and C. F. Varotto: J. Nucl. Mater., 46 (1973), 107.

(22) R. Tendler and C. F. Varotto: J. Nucl. Mater., 54 (1974), 212.

(23) G. M. Hood and R. J. Schultz: Acta Met., 22 (1974), 459.

(24) G. M. Hood and R. J. Schultz: Phys. Rev., B11 (1975), 3780.

(25) R. Tendler, J. Abriata and C. F. Varotto: J. Nucl. Mater., 59 (1976), 215.

(26) G. M. Hood: Phys. Rev., B23 (1981), 4253.

(27) E. Teatum, K. Gschneider and J. Waber: Report No. LA-2345, U.S. Dept. of Commerce, Washington, D.C., (1960).

(28) W. B. Pearson: The Crystal Chemistry and Physics of Metals and Alloys, Wiley, New York, (1972), p. 135.

(29) T. R. Anthony, B. F. Dyson and D. Turnbull: J. Appl. Phys., 39 (1968), 1391. 